\title{
The Wilms tumor suppressor WT1 regulates early gonad development by activation of $S f 1$
}

\author{
Dagmar Wilhelm ${ }^{1}$ and Christoph Englert ${ }^{2,3}$ \\ Institut für Toxikologie und Genetik, Forschungszentrum Karlsruhe, 76021 Karlsruhe, Germany
}

In mammals, several genes including the Wilms tumor suppressor gene Wt1, the Lim homeobox gene Lhx9, and the gene encoding steroidogenic factor 1 (Sf1) have been implicated in the development of the indifferent gonad prior to sexual differentiation. Interactions among these genes have not yet been elucidated. Using biochemical and genetic experiments, we demonstrate here that WT1 and LHX9 function as direct activators of the $S f 1$ gene. Interestingly, only the -KTS form of WT1 is able to bind to and transactivate the $S f 1$ promoter. This observation is consistent with differential roles for the -KTS and +KTS variants of WT1 which have been postulated on the basis of human disorders such as the Frasier syndrome. Our data suggest a pathway in which the products of the $W t 1$ and $L h \times 9$ genes activate expression of $S f 1$ and thus mediate early gonadogenesis.

[Key Words: Dax-1; Lhx9; transcription factor; zinc finger protein; transgenic mice; sex determination]

Received November 13, 2001; revised version accepted May 28, 2002.

In contrast to many other fundamental biological processes such as the control of the cell cycle or the formation of the body axes, sex determination does not seem to be evolutionarily conserved. In fact, this process shows remarkable plasticity and, to date, there is only one gene known, Dmrt1, which plays a role in sex development and is conserved among Caenorhabditis elegans, Drosophila, and mammals (Raymond et al. 2000).

The first phase of sex determination in mammals is the development of the bipotential (or indifferent) gonad. The latter arises as a thickening of the ventromedial surface of the mesonephros and is visible after $\sim 4 \mathrm{wk}$ of human embryonic development and at around embryonic day 10 (E10) in the mouse (Swain and Lovell-Badge 1999). This indifferent gonad is unique among organ primordia since it has the capacity to differentiate into two different organs, ovary or testis.

Factors that are involved in the establishment of the indifferent gonad include the product of the steroidogenic factor 1 (Sf1) gene, the Wilms tumor suppressor WT1, and the Lim homeobox protein LHX-9. The Sf1 gene encodes an orphan nuclear receptor that regulates the expression of several genes involved in steroidogenesis as well as gonadal development, such as members of the

Present addresses: ${ }^{1}$ Institute for Molecular Bioscience, The University of Queensland, Brisbane Qld 4072, Australia; ${ }^{2}$ Biozentrum der Universität Würzburg, Lehrstuhl für Physiologische Chemie I, Am Hubland, 97074 Würzburg, Germany.

${ }^{3}$ Corresponding author.

E-MAIL cenglert@biozentrum.uni-wuerzburg.de; FAX 49-931-888-4150. Article and publication are at http://www.genesdev.org/cgi/doi/10.1101/ gad.220102.
Cytochrome P-450 hydroxylases, Mis, and Dax-1 (Parker et al. 1999). The requirement of SF1 function for adrenal and gonadal development was demonstrated in humans and mice. A heterozygous inactivating mutation of SF1 was reported to be associated with male to female sex reversal and adrenal failure in a 2-week-old human patient (Achermann et al. 1999). In mice, inactivation of $S f 1$ does not seem to cause a phenotype in the heterozygous state, but targeting of both $S f 1$ alleles results in failure of adrenal and gonadal development (Luo et al. 1994). The gonads of $S f 1^{-1-}$ embryos do not develop beyond the early indifferent stage, and XY Sf1 mutant embryos display sex reversal in that the Müllerian ducts develop into uteri, oviducts, and upper vagina. The gonadal degeneration in $S f 1^{-/-}$embryos of either sex suggests that SF1 plays a fundamental role in gonad development.

The Wilms tumor suppressor gene WT1 (Wt1 in the mouse) was initially identified as a gene inactivated in a subset of Wilms tumors, a form of pediatric kidney cancer (Call et al. 1990; Gessler et al. 1990). A number of additional human diseases were shown to be associated with WT1 mutations (Englert 1998). Three of these disorders, namely the WAGR (Wilms tumor, aniridia, genitourinary abnormalities, mental retardation), DenysDrash (DDS), and the Frasier syndrome are characterized by urogenital abnormalities. These abnormalities are variable and can range from cryptorchidism and hypospadias in male WAGR patients to streak gonads and sex reversal of internal and external genitalia in extreme DDS and Frasier cases (Riccardi et al. 1978; Pelletier et al. 1991b; Barbaux et al. 1997; Kikuchi et al. 1998; Klamt 
et al. 1998). A more fundamental role for WT1 in gonad development is suggested by the analysis of the Wt1 knockout mouse. Inactivation of both Wt1 alleles results in embryonic lethality and leads to a failure of kidney and gonad development (Kreidberg et al. 1993). A thickening of the epithelium which gives rise to the gonad primordium can be observed in E11 Wt1-mutant embryos, but gonad development does not progress further. The migration of germ cells, however, is not affected by Wt1 mutation (Kreidberg et al. 1993). It is not known how WT1 contributes to early gonad development.

Expression of Wt1, which encompasses 10 exons, yields a protein family arising from usage of alternative translation initiation sites, RNA editing, and two alternative splicing events (I and II, reviewed in Englert 1998). Alternative splice I includes exon 5, which encodes 17 amino acids in the central part of the protein. The functional consequences of the inclusion of exon 5 have not yet been defined. Alternative splice II results from use of an alternative splice donor sequence between exons 9 and 10. Its insertion leads to three additional amino acids (the KTS sequence) that disrupt the spacing between the DNA binding zinc fingers 3 and 4 . These splice variants are expressed at a constant ratio whereby the +KTS isoforms constitute the majority of WT1 proteins in a cell (Haber et al. 1991). Interestingly, in Frasier patients this balance of the WT1 splice forms is disturbed due to intronic point mutations affecting the usage of donor splice sites in intron 9 of WT1. This suggests that the $-\mathrm{KTS}$ and +KTS isoforms of WT1 might play different roles in gonad development. This hypothesis was recently confirmed by the generation of the respective mouse models (Hammes et al. 2001).

WT1 was originally viewed as a potent transcriptional repressor for which multiple targets were described (Reddy and Licht 1996). Recent experiments, however, demonstrated that WT1 can also activate target genes including the cyclin-dependent kinase inhibitor encoding gene p21, Syndecan-1, Bc1-2, Dax-1, and Amphiregulin (Cook et al. 1996; Englert et al. 1997; Kim et al. 1999; Lee et al. 1999; Mayo et al. 1999). In the context of sex development, $\operatorname{Dax}-1$ is of particular interest because duplication of this gene leads to XY sex reversal in humans (Bardoni et al. 1994). In mice, inactivation of Dax-1 affects spermatogenesis, with the testes having half the normal weight (Yu et al. 1998).

An additional factor recently shown to control development of the early gonad is the product of the Lim homeobox gene Lhx9. In LHX9-deficient mouse embryos, a discrete gonad does not form and $S f 1$ expression is reduced to minimal levels (Birk et al. 2000). It is unclear whether LHX9 regulates $S f 1$ directly or indirectly.

Although a number of genes have been shown to play a role in the various stages of gonad development and sex determination, a sex development pathway has not yet emerged. In particular, it is still unclear which interactions exist among the genes required for development of the early indifferent gonad. We have sought to define the role of the Wilms tumor protein WT1 in early gonad development by studying changes in gene expression as- sociated with Wt1 inactivation. As a model system, we used the Wt1 knockout mouse. We demonstrate here that expression of the $S f 1$ gene in the early gonad is WT1dependent. In biochemical experiments, we identified and characterized four WT1 binding sites in the Sf1 promoter. These binding sites are located within a promoter fragment which is sufficient to activate reporter gene expression in the gonad of transgenic mice in a WT1dependent manner. In addition, our experiments show that another transcription factor, the product of the $L h \times 9$ gene, also binds to the $S f 1$ promoter and activates $S f 1$ expression. Our data suggest a very fundamental and early role for WT1 in gonad development and begin to define a hierarchy among the genes involved in early sex development.

\section{Results}

Sf1 is not expressed in $\mathrm{Wt}^{-/-}$gonads

To analyze differences in gene expression between normal and $W t 1^{-/-}$gonads, we isolated RNA from the gonads of wild-type and mutant embryos at days 10.5 and 11.5 of development. At these timepoints, the gonad is still undifferentiated, and RT-PCR analysis at both stages yielded identical results. As shown in Figure 1a, expression of Sox 9 and $L h x 9$ was not significantly affected by the inactivation of $W t 1$. In contrast, expression of Dax-1 and $S f 1$ was totally absent in mutant animals compared to wild-type controls. For Dax-1, regulation by WT1 was suggested previously but not shown to occur in vivo (Kim et al. 1999). For Sf1, this is the first indication that this gene is regulated by WT1. To determine whether WT1, which is expressed in the urogenital ridge from day E9 on (Armstrong et al. 1992), is involved in the initiation and/or maintenance of $S f 1$ expression, we performed a time-course experiment (Fig. 1b). Sf1 expression, which could first be observed at embryonic stage 9.5, was dependent on WT1 at this and all later stages examined. This suggests that WT1 is required for the initiation of $S f 1$ expression. We next wanted to confirm the RT-PCR data by an independent experimental approach and used in situ hybridization analysis. Complete absence of $S f 1$ expression in $W t 1^{-/-}$gonads at day 11.5 of development was also observed by in situ hybridization (Fig. 1c). To demonstrate the presence of an undifferentiated gonad at this stage of development, we used the marker $L h x 9$, which is only expressed in cells of the gonad and not in structures of the underlying mesonephros (Birk et al. 2000). Although mutant gonads were smaller than their wild-type counterparts, $L h x 9$ expression could clearly be observed in both cases. Thus both approaches demonstrate a complete absence of $S f 1$ expression in the early gonad of $W t 1^{-/-}$embryos.

\section{A 674-bp Sf1 promoter fragment is sufficient to activate reporter gene expression in the gonad in vivo}

To study whether the effect of the WT1 protein on Sf1 expression was direct or indirect, we first had to identify 
a

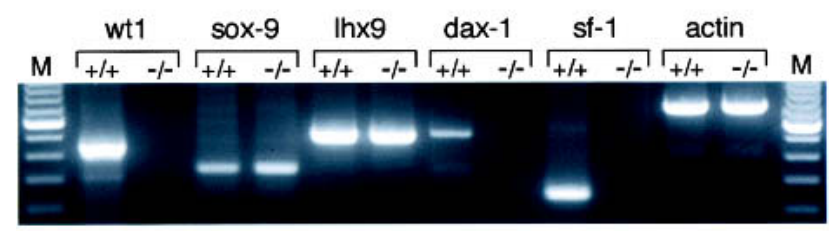

b

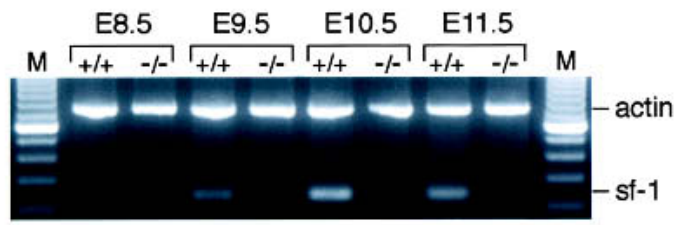

C
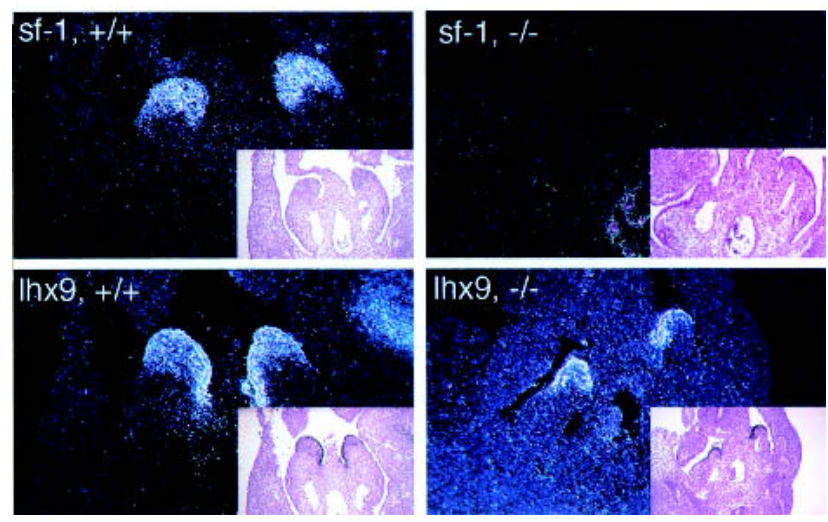

Figure 1. Analysis of gene expression in gonads from wild-type and Wt1-mutant embryos. (a) RT-PCR analysis using RNA from paired gonad/mesonephros complexes of wild-type and $W t 1^{-1-}$ embryos isolated at day 10.5 of embryonic development. The expected fragment sizes are $432 \mathrm{bp}$ (Wt1), $335 \mathrm{bp}$ (Sox9), 495 bp (Lhx9), 522 bp (Dax-1), 242 bp (Sf1), and 721 bp (Actin). M, 100 bp DNA marker. (b) RT-PCR analysis as in $a$ performed with RNA from different stages of development. (c) In situ hybridization analysis using radioactively labeled RNA probes: 7- $\mu \mathrm{m}$ transverse paraffin sections of wild-type (left) and Wt1mutant embryos (right) at stage E11.5 were hybridized with antisense probes against $S f 1$ (top) and Lhx 9 (bottom). For orientation, the respective bright field images are shown in insets. Both sections on the right are from the same embryo. Analysis shown in $a, b$, and $c$ was done with male embryos.

the region in the $S f 1$ promoter which is responsible for the expression of $S f 1$ in the gonad. It was shown earlier that a 90-bp fragment of the $S f 1$ promoter is sufficient to activate a reporter gene in steroidogenic cells (Woodson et al. 1997). To include additional cis-acting elements which might be required for $S f 1$ regulation in vivo, we used a DNA fragment encompassing nucleotides -590 to +85 of the $S f 1$ promoter which was cloned in front of the LacZ gene. With the use of this construct (named Sf1blue), transgenic mice were generated. Of seven potential founder animals, three expressed and passed on the transgene. In all three lines, $\beta$-Gal activity was observed in the gonads of E11.5 embryos. Expression levels differed significantly and ranged from low to very high (Fig. 2a). In addition to expression in the gonad, all lines showed $\beta$-Gal activity along the spinal cord. Sectioning of the embryos revealed staining of dorsal root ganglia as well as the ventrolateral region of the spinal cord /see Fig. 6c). These expression domains are presently unexplained, as neither $S f 1$ nor $W t 1$ has been reported to be expressed in these areas. Weak staining was also observed in the hindbrain region. This staining was also observed in nontransgenic controls and probably reflects a

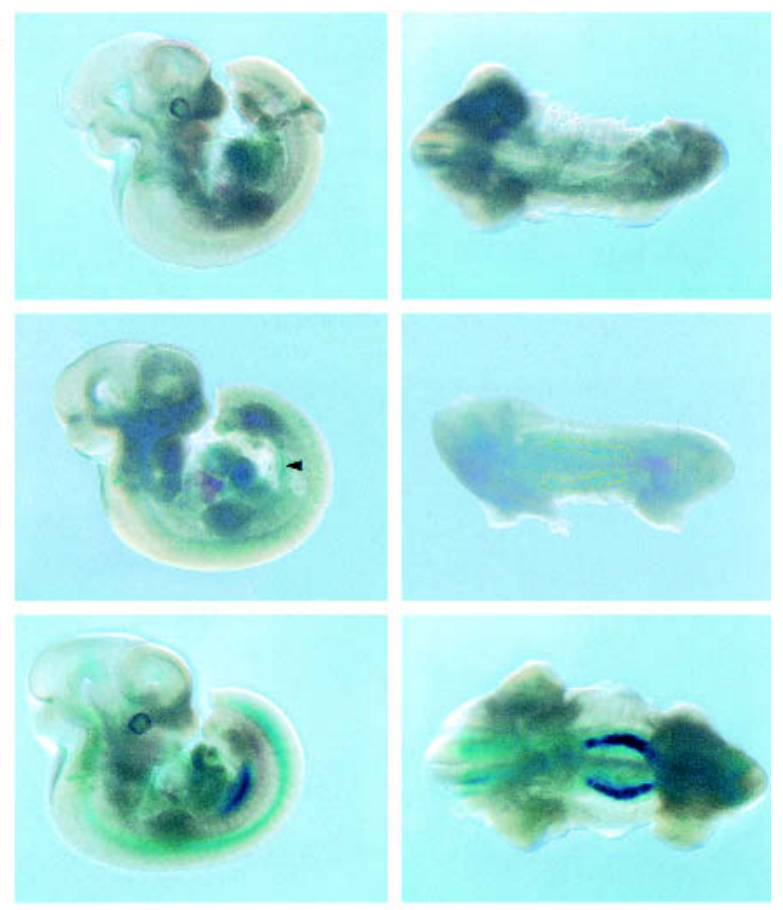

b

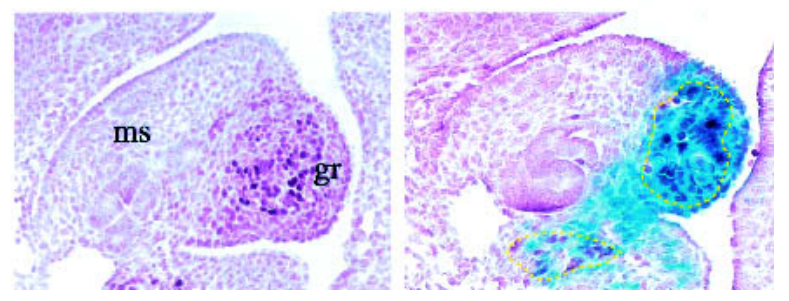

Figure 2. Analysis of mice transgenic for the Sf1-blue construct. The construct used harbors nucleotides -589 to +85 from the murine $S f 1$ promoter region followed by the LacZ gene carrying an NLS at its $5^{\prime}$ terminus. (a) X-gal staining of nontransgenic (upper panel) and transgenic embryos which express the transgene at low (middle panel) or high levels (bottom panel) are shown in a side (left) and top view (right). All animals were at stage E11.5, and the staining pattern and intensity were independent of the sex of the animals. The arrowhead and the dotted line demarcate the weakly stained cells in the gonads of the low-expressing line. (b) Colocalization of SF1 and $\beta$-Gal activity in an Sf1-blue embryo. X-gal stained nontransgenic (left) and transgenic (highly expressing, right) E11.5 embryos were processed into 7- $\mu \mathrm{m}$ transverse paraffin sections and then treated with an anti-SF1 antibody. SF1-positive cells appear dark purple. For better orientation, the area containing stained cells in the right panel is demarcated by a dotted line. gr, gonadal ridge; ms, mesonephros. 
ectopic reporter gene expression due to cryptic elements present in the LacZ gene (Moore et al. 1998). No transgene expression was seen in other organs normally expressing $S f 1$ such as the adrenal glands and the hypothalamus. Given the consistent $\beta$-Gal activity in the gonad of all animals examined thus far, we conclude that a 674-bp fragment of the $5^{\prime}$ region of the $S f 1$ gene contains regulatory elements which are sufficient for expression in the gonad in vivo.

To assess whether the same cells which express the $S f 1$ gene endogenously also display $\beta$-Gal activity, we performed a double labeling experiment. We used an anti-SF1 antiserum to analyze sections from nontransgenic and transgenic embryos which had been stained with X-gal. As described previously (Ikeda et al. 1994), $S f 1$ is expressed in the genital ridges of E11.5 embryos (Fig. 2b, left). This expression overlapped significantly with the expression pattern of the transgene; that is, almost every cell which was positive for SF1 also showed $\beta$-Gal activity (Fig. 2b, right). Thus with regard to gonadal $S f 1$ expression at the timepoint examined, the 674bp $S f 1$ promoter fragment used here seems to reflect the endogenous expression.

\section{Characterization of WT1 binding sites within the Sf1 promoter}

To determine whether the WT1 protein is able to bind to the Sf1 promoter, we performed a DNase I footprinting analysis. We made use of an internal BstXI site at position -210 of the $S f 1$ promoter and separated the 674-bp fragment into a distal (P5) and a proximal subfragment (P3). Our analysis revealed protection from DNase I digestion of four regions by the WT1(-KTS) protein but not by GST alone or WT1(+KTS) (Fig. 3a). One protected region (nucleotides -325 to -304 , WB1) was located within the distal fragment, and three regions (nucleotides -206 to -182 , WB2; nucleotides -83 to $-66, W B 3$, and nucleotides -49 to $-25, W B 4)$ were identified within the proximal fragment. The distal region encompassed an almost perfect WT1-response element (WTE) which had been previously defined as a high-affinity WT1 binding site (Nakagama et al. 1995). The sequence of the WTE is GC GTGGGAGT, whereas the $S f 1$ promoter harbors the element GGGTGGGAGT (nucleotides -309 to -318 in antisense orientation). The region centered on nucleotide -74 harbored an E-box, whereas the most proximal potential WT1 binding site overlapped in part with a GArich element (Fig. 4d). Both elements were previously shown to be essential for $S f 1$ promoter activity in steroidogenic cells (Woodson et al. 1997).

To confirm these sequences as WT1 binding sites, we performed electrophoretic mobility shift assays (EMSAs). Using labeled duplex oligonucleotides, WT1(-KTS) was shown to bind to all four sequences. In each case, introduction of a triple point mutation (Fig. 3c) abolished binding of WT1(-KTS) to the respective element. $\mathrm{WT} 1(+\mathrm{KTS})$ as well as a DDS patient-derived mutant form of WT1(-KTS) with an arginine to tryptophane ex- change at position 394 (Pelletier et al. 1991a) did not bind any of the probes (Fig. 3b; data not shown). Mutation of $W B 1$ within the distal $S f 1$ promoter fragment and WB2 to WB4 within the proximal fragment completely abolished WT1 binding. This indicates that there are no additional WT1 binding sites present within the Sf1 promoter fragment. Alignment of the four sites demonstrates the presence of a common GTGGG motif, which can also be found in the WTE sequence (Fig. 3c).

\section{Binding of LHX9 to the Sf1 promoter}

The absence of Sf1 expression in the gonads of $W t 1^{-/-}$ embryos demonstrates that WT1 is required for the activity of the $S f 1$ gene. It was recently shown that in gonadal tissue from embryos lacking the $L h x 9$ gene, only minimal $S f 1$ expression can be detected although the $W t 1$ gene is transcribed (Birk et al. 2000). This suggests that WT1 is necessary but not sufficient to activate $S f 1$ expression. The almost complete absence of $S f 1$ expression in $L h \times 9^{-/-}$embryos prompted us to examine whether the $L$ hx 9 gene product is able to bind to and activate the $S f 1$ promoter. Incubation of the distal $S f 1$ promoter region with recombinant GST-LHX9HD protein (C-terminus including the homeodomain) revealed protection of nucleotides -304 to -290 from DNase I digestion (Fig. 4a). In the proximal promoter fragment, no protection could be detected. The potential LHX9 binding site is immediately adjacent to the most distal WT1 binding site and harbors the sequence CGCTAA CAAGCCGC (Fig. 4d). EMSA experiments using oligonucleotides demonstrated that the homeodomain of LHX9 is sufficient for binding of the protected sequence (Fig. 4b). A mutated sequence CGCTCEACECAGCCGC was no longer bound by LHX9. Incubation of a labeled fragment encompassing the WT1 and the LHX9 binding sites with both recombinant proteins and subsequent EMSA analysis revealed the formation of an additional complex (Fig. 4c). This complex could be observed using the homeodomain of LHX9 as well as with the fulllength protein (data not shown). This indicates that at least in vitro, both proteins can bind the $S f 1$ promoter simultaneously.

\section{WT1(-KTS) and LHX9 activate the Sf1 promoter}

After having identified four WT1 binding sites and one LHX9 binding site within the Sf1 upstream region, we sought to determine whether both proteins could transactivate the $S f 1$ promoter in transfection experiments. For this analysis we used two different cell types, the murine Sertoli cell line TM4 and human U2OS-derived Wt1-inducible cell lines (Englert et al. 1995). Since both systems yielded virtually identical results, only those generated with the TM4 cells are shown. Expression analysis of these cells demonstrated absence of WT1 and SF1 at the protein level as well as absence of $L h \times 9$ mRNA. Cotransfection of Wt1(-KTS) expression constructs with the 674-bp Sf1 promoter fragment (SF1P, Fig. 5a) resulted in a moderate twofold activation of lu- 
a

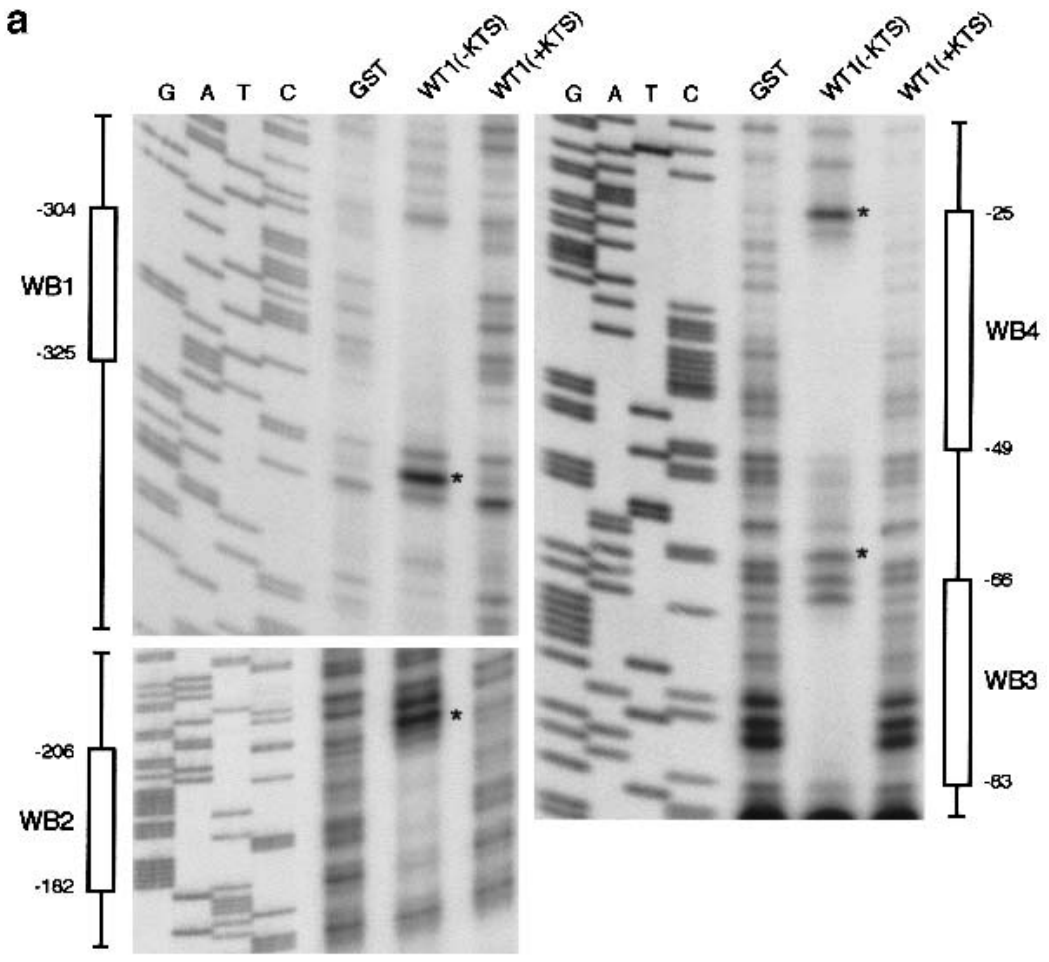

b
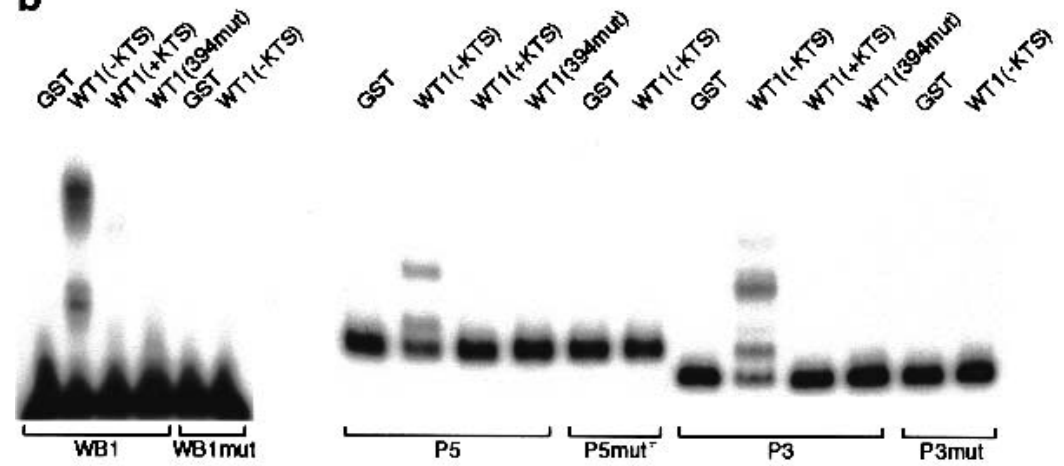

c

WTE:
WB1:
WB2:
WB3:
WB4:

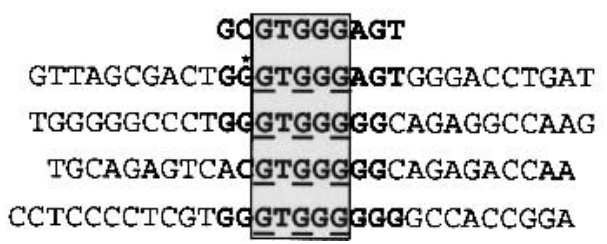

Figure 3. Identification of WT1 binding sites within the $S f 1$ promoter. (a) DNase I footprint analysis of the $S f 1$ promoter (nucleotides -589 to +85 ). A BstXI site at position -210 served to define a proximal (P3) and a distal promoter fragment (P5) which were used to characterize WB1 and $W B 3 / W B 4$, respectively. For $W B 2$, a fragment encompassing nucleotides -350 to -50 was used. The fragments were 5 '-labeled, incubated with recombinant GST (control), GST$\mathrm{WT} 1(-\mathrm{KTS})$, and GST-WT1 $1+\mathrm{KTS})$ protein and subjected to partial DNase I digestion. Sequencing reactions were performed using the same fragments as for the footprinting experiment. Four regions protected by GST-WT1(-KTS) are indicated by boxes. Four hypersensitive sites are marked by asterisks. (b) EMSA analysis of Sf1 promoter fragments using oligonucleotides constituting the WB1 site (left) as well as the distal (P5) and proximal (P3) Sf1 promoter fragments (right) as probes. Labeled oligonucleotides and fragments were incubated with recombinant GST, GST-WT1(-KTS), and GST-WT1(+KTS) protein as well as a mutant form of GSTWT1(-KTS) harboring a point mutation at position 394. The mutated WB1 probe contains three point mutations (described in $c$ ). The same experiments were done using probes $W B 2$ to $W B 4$. In the case of the P5 as well as the P3 fragment, all potential WT1 binding sites (WB1 to WB4) were mutated (P5mut, P3mut). (c) Alignment of the four WT1 binding sites within the Sf1 promoter. At the top, the high-affinity WT1 binding site (WTE) (Nakagama et al. 1995) is indicated. Sequences represent oligonucleotides which were used to characterize the WT1 binding sites in an antisense (WB1, WB2, and WB4) or sense (WB3) orientation. The asterisk marks the single mismatch between the WB1 site and the WTE. Exchange of the underlined nucleotides into thymidine residues abolishes WT1-binding. The GTGGG motif which all the WT1 binding sites have in common is boxed and shaded. ciferase activity (Fig. 5b). Introduction of point mutations into any of the WT1 binding sites resulted in an increase in WT1-mediated activation (shown here for WB3). This suggests that in this system, WT1 can also exert some repressive function. The +KTS form of WT1 did not have any effect in this assay. To identify the sites which mediated the activation, we used the distal and proximal Sf1 promoter fragments independently. Whereas the proximal subfragment encompassing sites $W B 2, W B 3$, and WB4 did not significantly stimulate reporter gene activity upon $W t 1$ cotransfection (data not shown), the distal fragment (P5) harboring WB1 was ac- tivated by WT1(-KTS) fivefold. The next series of experiments was therefore performed using the reporter construct harboring the distal fragment only. Cotransfection of this construct with an $L h x 9$ expression vector resulted in a 2.5-fold activation in the absence of WT1. Together with WT1(-KTS), however, LHX9 led to eightfold activation. This result shows that at least in the system employed here, WT1 and LHX9 bind simultaneously and have an additive effect in activating the $S f 1$ promoter fragment. Mutational analysis of the WT1 binding site and the LHX9 binding site in the distal promoter fragment demonstrated that both sites function indepen- 

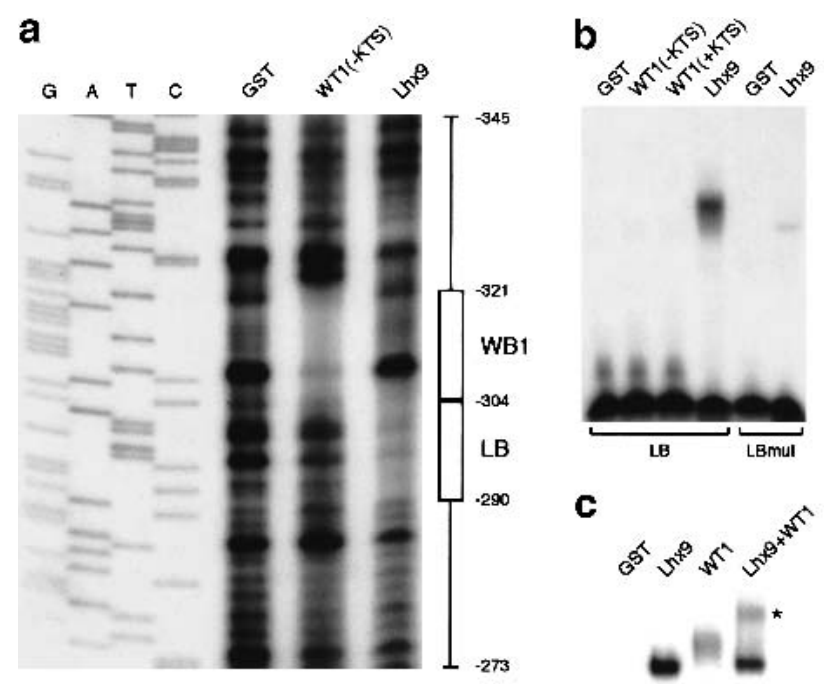

C

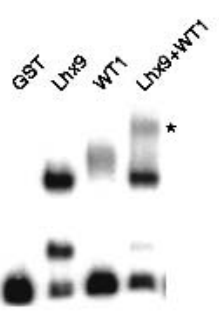

-599 CACACCCTTAGCCCAGCAGTCTTGGCACAACCTCAGTTTCCCCAGCTACCAATGGACCAT 529 ATCTGCAGCTCCCAGAGAaGCCACCAAAARGGCCACACAMACCCCACCTTGATGGGTTCC 469 ACCATGCCATTTCTCCACACTAGCCATTCTGACTCCTCACTCAGATCTGGGACAAGCTGG

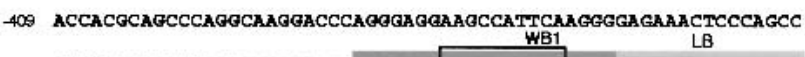
349 TGGTAAGgGaCAGGCCATAAATCAGGTCC ACTCCCACCO GTCGCTAACAAGCCGCTG 289 CCTATCTGCCTACATGGGGTCCCTOCCTCAGGCTCCCTCATCAGCCTGGACAGCCAGCTG -229 GTCAAGTCTCTCCAGTGCCTTGGCCTCTGCCCCCACCCAGGGCCCCATAAAGATAGGG

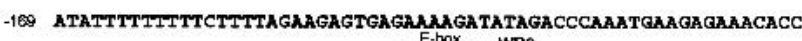

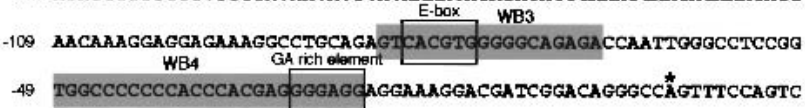
12 CGCCGCTGCCCGCCCGCTGCTGGGTGAAGAGTTTCTGAGAGCCCGCTAGCCACTGCCCT

12 ACCTGAGgCCTGGg as

Figure 4. Identification of an LHX9 binding site within the $S f 1$ promoter. (a) DNase I footprinting analysis of the distal $S f 1$ promoter fragment (nucleotides -589 to -210 ). The DNA fragment was end-labeled, incubated with recombinant GST (control), GST-WT1(-KTS), and GST-LHX9HD protein and subjected to partial DNase I digestion. A sequencing reaction was performed using the same fragment as for the footprinting experiment. The regions protected by WT1(-KTS) and LHX9 are indicated by boxes. (b) EMSA analysis of the LHX9 binding site using wild-type and mutant oligonucleotide probes. (c) EMSA analysis of an $S f 1$ promoter fragment encompassing nucleotides -589 to -284 . The asterisk marks a complex present only when WT1(-KTS) and LHX9HD are used simultaneously. (d) Sequence of the murine $S f 15^{\prime}$-flanking region. Nucleotide numbers, the positions of the E-box, and the GA-rich element as well as the position of the transcriptional start site refer to a published promoter sequence (Woodson et al. 1997). WT1 binding sites as revealed by DNase I footprinting and EMSA analysis are highlighted by gray shading. A WTE-like element around position -314 is boxed. The LHX9 binding site is shaded in light gray.

dently, because mutation of the WT1 binding site did not affect the activation by LHX9, and vice versa (Fig. 5b). Interestingly, we found a consistent repression of the WT1-mediated activation of fragment $\mathrm{P} 5 \mathrm{~m} 2$ (harboring a mutation of the LHX9 binding site) upon cotransfection of $L h \times 9$. Finally, the introduction of point mutations into all four WT1 binding sites within the complete 674bp fragment led to a complete loss of promoter activity upon Wt1(-KTS) cotransfection. This confirms the conclusion from the EMSA experiments and suggests the absence of additional functional WT1 binding sites within this region.

To examine whether expression of the endogenous $S f 1$ gene could be induced by $W t 1$ overexpression, we performed an RT-PCR analysis in the Wt1(-KTS)-inducible U2OS cell line. Upon induction of Wt1, however, no activation of $S f 1$ expression could be detected (data not shown). This is in line with the published observation indicating that Wt1 expression is not enough to stimulate the endogenous Sf1 promoter (Birk et al. 2000) and can most likely be explained by the absence of cofactors.

\section{Expression of LacZ in the gonad of Sf1-blue mice is WT1-dependent}

To examine whether $L a c Z$ expression observed in the gonad of $S f 1$-blue transgenic mice requires the activity of WT1, we performed two types of experiments. First, we bred transgenic animals into the Wt1-mutant background. Upon crossing of transgenic males which were heterozygous for the Wt1 mutation with a $\mathrm{Wt1}^{+/-}$female, embryos of different genotypes were obtained and assayed for $\beta$-Gal activity at stage E11.5 of development. Whereas transgenic embryos without or with one mutated $W t 1$-allele displayed $\beta$-Gal activity in the gonads, $\mathrm{X}$-gal staining of the gonads was almost completely lost in transgenic $\mathrm{Wt1}^{-/-}$littermates (Fig. 6a). Ectopic LacZ expression in the spinal cord, however, was maintained in Wt1 knockout animals. Upon characterization of additional transgenic animals, we noted a difference in $\beta$-Gal activity between wild-type and heterozygous Wt1embryos. Indeed, subsequent analysis of littermates revealed a dependence of the gonad expression domain but not the LacZ expression along the spinal cord on the Wt1-gene dosage; that is, in all cases examined, heterozygous Wt1 embryos showed much weaker staining of the gonads compared to wild-type littermates (Fig. 6b). This seemed to be caused by a lower expression level per cell as well as by a smaller number of cells which expressed the transgene (Fig. $6 \mathrm{~b}$ ). At this stage, $\beta$-Gal activity was independent of the sex of the respective animal. Given the absence of any phenotypic differences between $\mathrm{Wt1}^{+/-}$and wild-type animals, the decrease in LacZ transgene expression in $W t 1^{+/-}$and $\mathrm{Wt}^{-1-}$ animals is not a consequence of loss of a specific cell population but rather a direct result of the reduction of WT1 activity. This gene dosage effect was observed in all three Sf1-blue lines.

To investigate whether WT1 acts directly on the $S f 1$ promoter fragment, we generated transgenic mouse lines using the Sf1-blue construct in which all four WT1-binding sites had been mutated. This construct was named Sf1-white. Six independent lines were characterized, which all showed X-gal staining along the spinal cord, as 
a
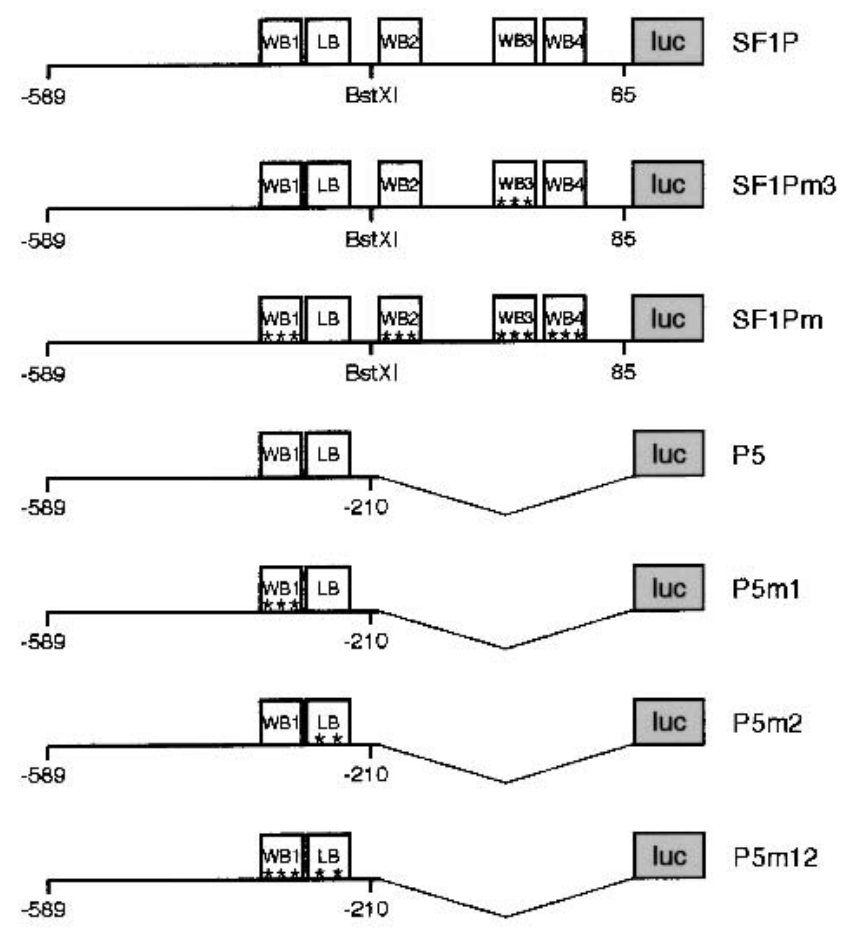

b

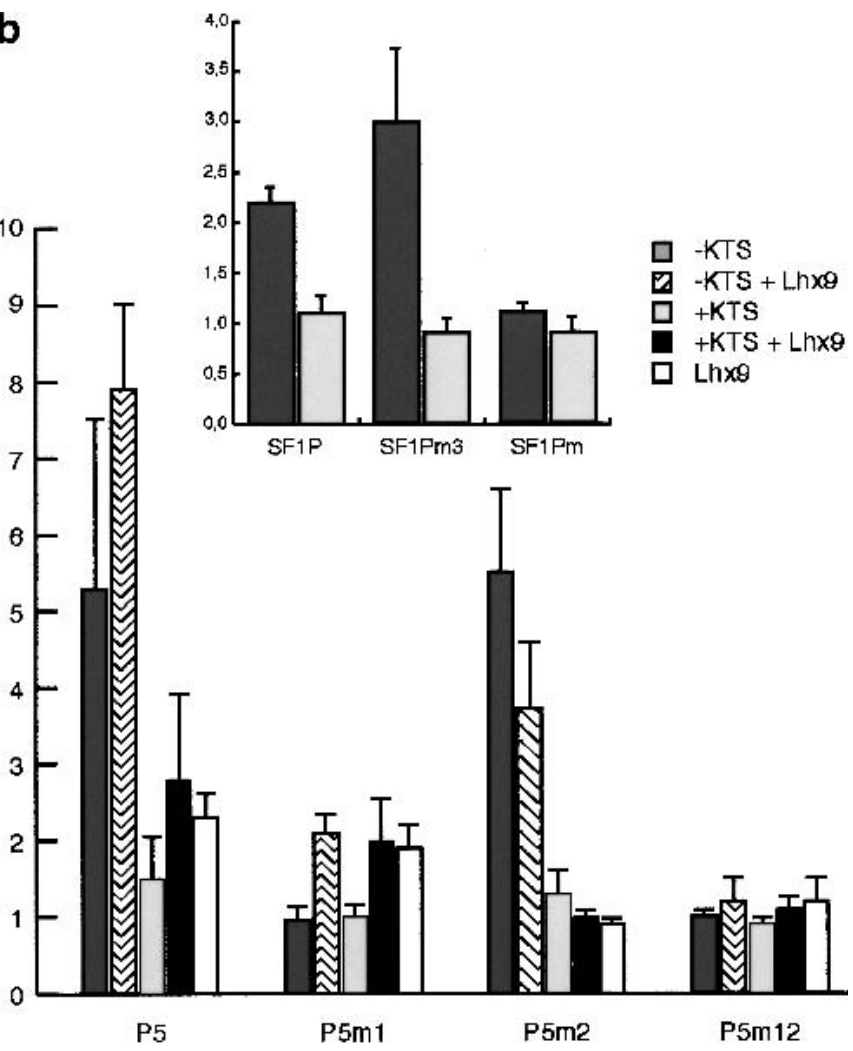

Figure 5. Activation of the $S f 1$ promoter by WT1 and LHX9. (a) Schematic representation of the luciferase reporter constructs used. Positions of the four WT1 binding sites, the LHX9 binding site (LB), as well as the BstXI site are indicated. The promoterless reporter vector pGL3basic was used as a backbone. Point mutations are indicated by asterisks. $(b)$ Activation of the $S f 1$ promoter by WT1 and LHX9. TM4 cells were cotransfected with different $W t 1$ and $L h \times 9$ expression plasmids and the respective reporter constructs. Results are given as relative activation of the reporter by the expression constructs compared to the empty vector. Data represent the mean and standard deviation of three independent experiments.

did the Sf1-blue mice. In contrast to the latter, however, no expression of $L a c Z$ could be observed in the gonads of the Sf1-white embryos (Fig. 6c). We conclude from these experiments that the WT1 protein is responsible for the activity of the 674-bp $S f 1$ promoter fragment in vivo.

\section{WT1 ${ }^{-/-}$embryos show no signs of sexual development}

The targeted inactivation of $S f 1$ leads to death of the embryos by postnatal day 8 and is characterized by a lack of adrenal and gonad development (Luo et al. 1994). Despite the failure of gonadal organogenesis, XY and XX Sf1 mutant mice have female internal genitalia including oviducts, uteri, and vagina. Homozygous deletion of Dax-1 does not interfere with gonad development per se but leads to a progressive degeneration of the testicular epithelium resulting in male sterility (Yu et al. 1998). Normally $\mathrm{Wt}^{-1-}$ embryos die between stage E13.5 and E15.5, but we recently demonstrated that crossing the Wt1 mutation into a different mouse background (MF1) prolongs the lifespan of mutant animals until birth (Herzer et al. 1999). Prompted by our observation that WT1 regulates both $S f 1$ and Dax-1 in vivo, we examined the development of the internal genitalia on serial sections of wild-type and Wt1 mutant embryos at stages E13.5 and E18.5. We detected no signs of internal reproductive organs of either sex in $\mathrm{Wt1}^{-{ }^{-}}$embryos; that is, in addition to the lack of gonad development, no derivatives of the Müllerian duct (uterus, oviducts, upper vagina) or the Wolffian duct (seminal vesicles, epididymis, vas deferens) were seen (data not shown). This indicates that in terms of sex development the phenotype associated with the inactivation of Wt1 is more severe than the one caused by deletion of $S f 1$ or Dax-1. This observation is in agreement with our molecular analysis indicating that the Wt1 gene is located upstream of both Dax-1 and Sf1.

\section{Discussion}

A large number of genes regulated by WT1 have been characterized (Menke et al. 1998). In these cases, WT1 can function as both a repressor and an activator of transcription. The different WT1 targets have mostly been identified on the basis of the similarity of promoter sequences with WT1 binding sites and subsequent transient transfection experiments. There has not been a good correlation, however, between the results of transient transfections and the regulation of the respective 
a

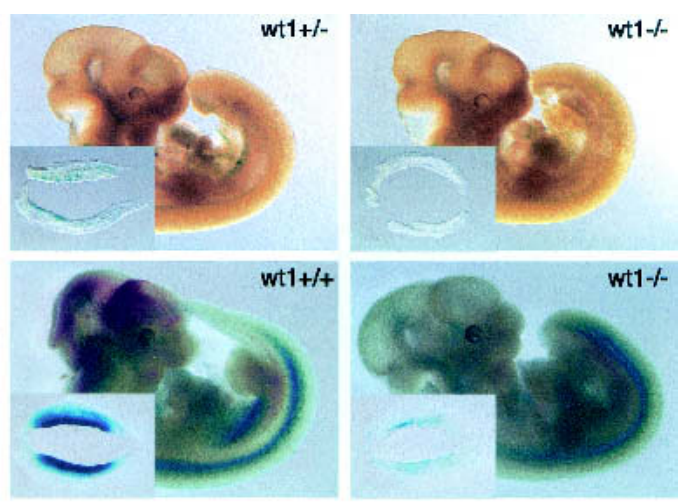

b

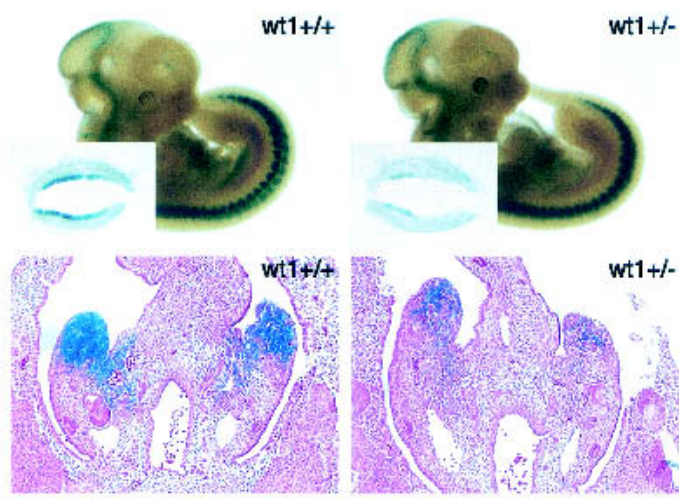

C
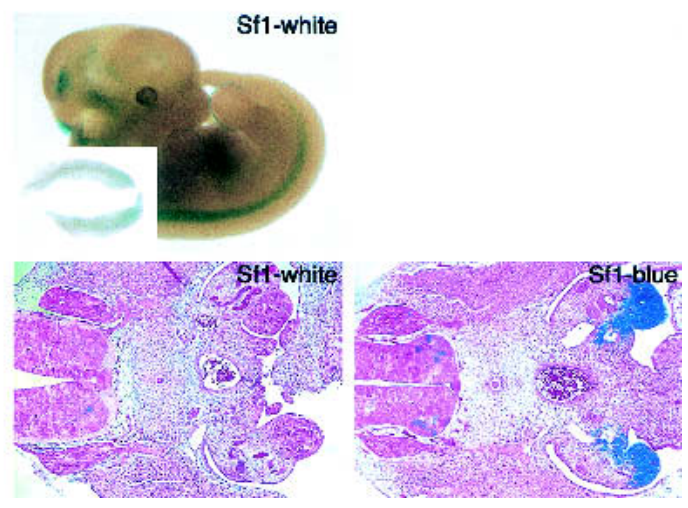

Figure 6. LacZ expression in the gonad of Sf1-blue mice is WT1-dependent. (a) Transgene expression is severely reduced in $W t 1^{-1-}$ embryos. Sf1-blue mice were crossed into the Wt1-mutant background. X-gal staining was performed using embryos of different genotypes at stage E11.5 of two different Sf1-blue mouse lines (top, intermediate expressing line; bottom, highly expressing line). Insets show the isolated gonadal and mesonephric structures. (b) Transgene expression depends on the Wt1 gene dosage. A comparison of X-gal stained wild-type and $W t 1^{+/-}$whole embryos (upper panel) and transverse sections (lower panel) of an Sf1-blue line (intermediate expressing line) is shown. (c) Analysis of mice transgenic for the Sf1-white construct which harbors nucleotides -589 to +85 from the murine $S f 1$ promoter region with triple point mutations in each of the four WT1 binding sites followed by the LacZ gene carrying an NLS at its $5^{\prime}$ terminus. Transgenic embryos at stage E11.5 were

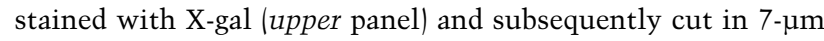
sections (lower panel). For comparison, a section of an X-galstained Sf1-blue embryo is shown. All animals shown in this figure are heterozygous with regard to the transgene. endogenous promoter sequences (Englert et al. 1995; Thate et al. 1998). Large-scale expression profiling with RNA from Wt1-inducible cells has been used to search for WT1 targets, and Amphiregulin was identified as a gene activated by WT1 (Lee et al. 1999). In no case, however, has the Wt1 knockout mouse been used to verify the physiologic significance of an interaction. To identify genes mediating the function of WT1 during gonad development, we analyzed gene expression in the early gonad of wild-type and Wt1-mutant embryos. Our analysis shows that the expression of the Dax-1 and $S f 1$ genes depends on the presence of WT1. This extends the earlier observation that Dax-1 is activated by WT1 (Kim et al. 1999) and shows that this interaction is also relevant in vivo.

With $S f 1$ we have identified the first physiologic WT1 target which mediates its function in early gonad development. Our data suggest that WT1 is required for the initiation of $S f 1$ expression, because even at the earliest timepoint where Sf1 expression can be observed (E9.5; Ikeda et al. 1994, our data), it is absent in Wt1-mutant embryos. In addition to in situ and biochemical analyses, the strongest support for $S f 1$ being a genuine WT1 target comes from in vivo experiments using transgenic mice. Crossing of mice carrying a $L a c Z$ reporter gene under the control of an Sf1 promoter fragment into a Wt1-mutant background revealed a dependence of transgene expression on WT1 activity. This dependence was sensitive to Wt1 gene dosage as shown by a comparison of transgenic wild-type and $W t 1^{+/-}$littermates. No difference between wild-type and heterozygous Wt1-animals has been reported to date, and all available evidence points to normal development of the gonads in $\mathrm{Wt1}^{+/-}$animals (Kreidberg et al. 1993; our data). Thus, reduction of transgene expression associated with Wt1 heterozygosity is not a consequence of degeneration of the gonads and can best be explained by a direct effect of WT1 on the $S f 1$ promoter. This is corroborated by our observation that an $S f 1$ promoter construct with mutated WT1 binding sites is not able to drive reporter gene expression in the gonads.

In this study we focused on a 674-bp fragment of the Sf1 promoter encompassing elements which had been shown to activate reporter gene expression in steroidogenic cells (Woodson et al. 1997). Given the size of the fragment, it seems unlikely that it is able to mimic full endogenous $S f 1$ expression. Nevertheless, this fragment activated $L a c Z$ expression in the indifferent gonad at stage E11.5 of transgenic mouse embryos, suggesting that it harbors elements which are sufficient to direct $S f 1$ expression in the gonad in vivo. Our analysis of the interaction between WT1 and the $S f 1$ promoter fragment suggests that this interaction is direct. Binding of WT1 to the $S f 1$ promoter in vitro occurs via four binding sites which all share the motif GTGGG. This sequence can also be found in the high-affinity WT1 binding site GC GTGGGAGT (Nakagama et al. 1995). From our analysis and previous data, one can therefore derive the consensus $\mathrm{Pu} / \mathrm{G} / \mathrm{C})$ GTGGGPuG for a WT1 binding site.

With regard to its transcriptional activity, it is inter- 
esting to note that while WT1 acts as an overall activator of the $S f 1$ promoter, in the transient transfection system employed here, WT1 also exerted some repressive activity. Whereas WT1 activated the 674-bp Sf1 promoter fragment or subfragments thereof, mutation of any single WT1 binding site resulted in an even higher activation level. This is reminiscent of the PDGF A-chain promoter, where occupancy of multiple binding sites by WT1 was associated with transcriptional repression, and binding to a single site led to activation (Wang et al. 1993). At this point it seems appropriate to point out that the extrapolation of observations generated by using in vitro systems like transient transfection experiments to the situation in vivo must be made with great caution. This is also exemplified by the fact that whereas small $S f 1$ promoter fragments could be activated by WT1 in the transient transfection system, expression of the endogenous $S f 1$ gene could not be achieved by $W t 1$ expression alone. This is probably due to the lack of additional factors. Nevertheless, our results confirm earlier observations about the bipotential nature of the WT1 protein (Reddy et al. 1995) and suggest that the amount of available WT1 protein is critical in determining the transcriptional activity of WT1.

An additional protein which influences $S f 1$ expression is the product of the $L h \times 9$ gene (Birk et al. 2000). Our biochemical analysis shows that LHX9 can bind directly to the $S f 1$ promoter. The binding site encompasses the motif TAACAA, which upon mutation to TCACCA can no longer be bound by LHX9. To our knowledge this sequence, which shows similarity but is not identical to any of the presently known LIM homeodomain gene targets (Jurata and Gill 1998), is the first LHX9 binding site described. Interestingly, all four WT1 as well as the LHX9 binding sites are conserved between the mouse and the human $S f 1$ promoter (Woodson et al. 1997). The interaction between WT1, LHX9, and the $S f 1$ promoter is reminiscent of the situation described for the Mis promoter. For normal Mis expression to occur, the activity of two transcription factors, SF1 and SOX9 is required. Whereas SOX9 plays an essential role in the initiation of Mis transcription, SF1 has a more modulatory role in regulating transcript levels (Arango et al. 1999). Given the proximity of the WT1 and the LHX9 binding site within the distal $S f 1$ promoter sequence, one could speculate that, as in the case of SOX9 and SF1 (De Santa Barbara et al. 1998), the two factors might interact with each other. This could lead to a reciprocal sequestration and might explain the repressive effect of LHX9 overexpression on WT1-mediated transactivation of a promoter fragment with a mutated LHX9 binding site.

A fascinating aspect of the biochemistry and biology of the WT1 protein is the existence of the various splice forms. In particular, the -KTS and the more prevalent + KTS forms, differing only by a 3 -aa insertion in the zinc finger region (Haber et al. 1991) have led to many speculations about their different roles in the etiology of diseases. Are there different roles for the WT1(-KTS) and the WT1 $1+$ KTS $)$ form in sex development? The answer is clearly, yes. First, patients with an altered ratio of these particular splice forms show abnormalities in urogenital development and function (Barbaux et al. 1997; Kikuchi et al. 1998; Klamt et al. 1998). Second, it is the -KTS form of WT1 which is able to bind to and synergize with SF1 in the activation of the Mis gene (Nachtigal et al. 1998). Third, our analysis shows that it is again only the -KTS form which is able to bind to and transactivate the $S f 1$ promoter. Based on these findings, we would predict a more fundamental role for the -KTS form compared to the + KTS variant in gonad development. This was indeed recently confirmed by the generation of mouse lines which express exclusively either the +KTS or the -KTS isoform of WT1 (Hammes et al. 2001). The analysis of the animals revealed a requirement of the $-\mathrm{KTS}$ variants for the survival of the gonadal primordium, whereas the + KTS forms seem primarily involved in the male sex determination pathway. Interestingly, Wt1 null mice display a more severe gonadal phenotype than those with deletion of the WT1(-KTS) splice form. This might be explained by a partial compensation of one splice form by the other.

How can one interpret the role of WT1 as a transcription factor in the context of gonad development? Previous work (Kreidberg et al. 1993) and our own observations demonstrate that in the absence of WT1, the gonad develops only to an early timepoint of the indifferent stage. After E11.0-E11.5, significant differences between wild-type and mutant gonads become visible, and two days later no remnant of the gonad can be observed in Wt1 mutant animals. Thus, the activity of WT1 is required for the gonad to develop from an early into a late bipotential stage. Our data suggest that one critical mediator of WT1's function in early gonadogenesis is the Sf1 gene. Together with LHX9, WT1 binds to and activates the $S f 1$ promoter, leading to the expression of this key regulator of gonadogenesis. Interestingly, in terms of growth control, the activation and not the repression function of WT1 seems to be the critical transcriptional activity (English and Licht 1999). Our experiments also confirm that the Dax-1 gene is downstream of WT1. As suggested earlier, this regulation could be direct (Kim et al. 1999). However, it was demonstrated that Dax-1 can be regulated by the SF1 transcription factor (Kawabe et al. 1999), and it thus remains possible that the activation of $D a x-1$ by WT1 is indirect. The role of $D a x-1$ in early gonad formation has not been firmly established. The inactivation of $W t 1$ has more marked phenotypic consequences than deletion of either Dax-1 or $S f 1$ alone (Luo et al. 1994; Yu et al. 1998). Although it is conceivable that simultaneous deletion of $S f 1$ and $D a x-1$ from the germline results in a more severe phenotype, it seems more likely that WT1-also given its broader expression domain-regulates additional genes during urogenital development. These could be genes which are activated or repressed by WT1. The identification of additional critical target genes of WT1 which mediate its role in urogenital development as well as the characterization of the cofactors involved will eventually lead to a better understanding regarding the function and mechanism of this pivotal transcription factor. 


\section{Materials and methods}

\section{Mouse lines}

A $\mathrm{Wt}^{+/-}$breeding pair was obtained from The Jackson Laboratory and maintained on a C57BL/6J background. Embryos were collected from timed matings, with noon of the day on which the mating plug was observed designated E0.5. Genotyping was done by PCR using primers Wt1-pgk (CTACCGGTGGATGTG GAATGTGT), Wt1-shared (TCCCGAACAATTTCACCTTGA ATC), and Wt1-wt (AGCCTAACTTTGGGGCTTATCTCC) in a single tube. The product generated from the wild-type allele comprises 140 nucleotides, and that from the mutant allele 200 nucleotides. Presence or absence of the Y chromosome was analyzed by PCR using $Z f_{y}$ - and Sry-specific primers as described (Hogan 1994).

\section{RT-PCR analysis}

Tissue comprising the trunk (at stages E8.5 and E9.5) or mesonephros and gonad (at stages E10.5 and E11.5) was isolated from mouse embryos of different genotypes. Polyadenylated RNA was then prepared using Dynabeads (Dynal) according to the manufacturer. The RNA was resuspended in a final volume of $10 \mu \mathrm{L}$ (per embryo). First-strand cDNA synthesis was done at $45^{\circ} \mathrm{C}$ for $1 \mathrm{~h}$ using $5 \mu \mathrm{L}$ of the RNA preparation with SuperScript II (GIBCO BRL) in the presence of $100 \mathrm{ng}$ of oligo-dT15 primers in a volume of $20 \mu \mathrm{L}$. A parallel reaction without reverse transcriptase (RT) was performed in each case. The cDNA was diluted 1:5 in water, and $5 \mu \mathrm{L}$ of the RT reaction was used for PCR analysis. A positive control and several negative controls (no template, no RT) were included in each experiment. PCR was done at an annealing temperature of $55^{\circ} \mathrm{C}$ using 35 cycles for all primer pairs except for Actin (20 cycles). Each RT-PCR was repeated at least three times with RNA from different embryos.

Primer pairs used were Wt1-5' (GGGGAAGCTTCCGCCA TGGGTTCCGACGTGCGGGAC) and Wt1-3' (GGATGGTAGG CTGGCTCTCCAG), Sox9-5' (GCCGACTCCCCACATTCCT CC) and Sox9-3' (GCCGTAACTGCCAGTGTAGGTG), Lhx9-5' (ACGTTCTAGAAGCTCTGGGAGTGGACATCG) and Lhx93' (ACGTGGGCCCTTAGAAAAGGTTCGTTAAGGTAGT), Dax1-5' (GTCAAGTACTTGCCCTGCTTCCA) and Dax1-3' (GATGAATCTCAGCAGGAAAAGGGC), Sf1-5' (GTGAAAT TCCTGAACAACCACA) and Sf1-3' (GTCTGCTTGGCCTG CAGCAT), as well as Actin-5' (AGAGGTATCCTGACCCTG AAGTACC) and Actin-3' (CCACCAGACAACACTGTGTTG GCAT).

\section{RNA in situ hybridization}

In situ hybridization using serial transverse sections $(7 \mu \mathrm{m})$ of paraformaldehyde-fixed and paraffin-embedded, staged mouse embryos were performed according to standard procedures (Hogan 1994; Belo et al. 1997). A 265-bp fragment derived from the $3^{\prime}$-untranslated region of the mouse Sf1 cDNA $1+3481$ to +3746 ) and a 1133-bp fragment from the coding region of mouse Lhx $9(+4$ to +1137$)$ was cloned by PCR using cDNA from urogenital ridges of C57BL/6J embryos into the pGEM-T easy vector (Promega). Constructs were sequenced and used for in vitro transcription of antisense and sense control of ${ }^{35}$ S-labeled RNA probes. Additional hybridizations with identical results were performed with a second nonoverlapping $S f 1$ probe comprising the entire coding region.

\section{Luciferase reporter assays}

An $S f 1$ promoter fragment encompassing nucleotides -589 to +85 (Woodson et al. 1997) was generated by PCR using genomic
C57BL/6J DNA as a template and cloned into the SacI and Bg/II sites of the pGL3basic luciferase reporter vector (Promega). An internal BstXI site at position -210 was used to define a distal and a proximal promoter element. The respective subfragments were generated by PCR and cloned into the SmaI site of pGL3basic. For the introduction of mutations, the QuikChange kit (Stratagene) was used. The integrity of all constructs was verified by sequencing. The $L h \times 9$ expression construct was made by RT-PCR using polyadenylated RNA from urogenital ridges of C57BL/6J mouse embryos (E11.5) followed by cloning of the PCR product $(+4$ to +1137$)$ into the EcoRI and ApaI sites of RcCMV (Invitrogen). The vector had previously been modified so that the second EcoRI site $(+1744)$ was deleted. In addition, two complementary oligonucleotides had been inserted between the HindIII and EcoRI sites constituting an HA-epitope tag. Wt1 expression constructs encompassing the entire Wt1 coding region (with and without the KTS insertion) were cloned by PCR using Wt1 cDNAs (Haber et al. 1993) as templates into the HindIII and $\mathrm{XbaI}$ sites of the unmodified RcCMV vector.

The murine Sertoli cell line TM4 (obtained from the European Collection of Cell Cultures, ECACC) was grown in DMEM supplemented with $10 \%$ FCS. Two cell lines derived from human osteosarcoma U2OS cells (UB27 and UD28) were grown in DMEM supplemented with $10 \%$ FCS, $1 \mu \mathrm{g} / \mathrm{mL}$ tetracycline, and antibiotics. The generation of UB27 and UD28 cell lines harboring inducible $W t 1(-K T S)$ and $W t 1(+K T S)$ alleles, respectively, has been described (Englert et al. 1995). Cells were split at $1.2 \times 10^{5}$ cells per well into 6-well dishes and transfected 24 $\mathrm{h}$ later with $0.6 \mu \mathrm{g}$ of reporter plasmid, $0.7 \mu \mathrm{g}$ of expression plasmid, and $0.1 \mu \mathrm{g}$ of internal control plasmid encoding Renilla luciferase (with a total of $2 \mu \mathrm{g}$ of plasmid DNA per well) using SuperFect (QIAGEN) as described by the manufacturer. UB27 and UD28 cells were kept in tetracycline-containing medium, that is, Wt1 expression was repressed until transfection was performed. Reporter gene activity was determined $48 \mathrm{~h}$ after transfection using the Dual-Luciferase system (Promega). Values were normalized for transfection efficiency and with respect to the effects of the expression constructs on the empty pGL3basic reporter plasmid.

\section{Electrophoretic mobility shift assays}

EMSA analysis was performed using recombinant, bacterially expressed GST fusion proteins of the zinc finger region of WT1 with or without the KTS insertion, a Denys-Drash mutant harboring an exchange of Arg at position 394 to a Trp residue (Pelletier et al. 1991a), full-length LHX9 (GST-LHX9), and the Cterminus including the homeodomain of LHX9 (aa 215-378, GST-LHX9HD). Recombinant plasmids were constructed using the vector pGEX-KG (Guan and Dixon 1991).

$S f 1$ promoter fragment probes were cut out of the respective pGL3 reporter constructs and gel-purified. Oligonucleotide probes harboring the LHX9 binding site had the following sequences: CCCACCCAGTCGCTAACAAGCCGCTGCCTATC (wild type) and CCCACCCAGTCGCTCACCAGCCGCT GCCTATC (mutant). Fragments as well as oligonucleotide probes were labeled using $\left[\gamma^{-}{ }^{32} \mathrm{P}\right] \mathrm{ATP}$ and T4 polynucleotide kinase for $1 \mathrm{~h}$ at $37^{\circ} \mathrm{C}$ and subsequently purified using Nick columns (Amersham). Binding reactions were performed in a final volume of $30 \mu \mathrm{L}$ in binding buffer $100 \mathrm{mM} \mathrm{KCl}, 1 \mathrm{mM}$ $\mathrm{MgCl}_{2}, 10 \mu \mathrm{M} \mathrm{ZnSO}_{4}, 10 \mathrm{mM}$ Tris, $\mathrm{pH} 7.5,4 \%$ glycerol, $0.1 \%$ Triton X-100, $1 \mathrm{mg} / \mathrm{mL}$ BSA, $1 \mu \mathrm{g}$ of poly(dIdC)/poly(dAdT), 0.5 $\mathrm{mM}$ DTT). Reaction mixtures containing $20 \mathrm{ng}$ of purified protein were preincubated for $10 \mathrm{~min}$ at room temperature followed by the addition of $3000 \mathrm{cpm}$ of end-labeled probe. After a 30-min incubation at room temperature, DNA-protein com- 
plexes were resolved by electrophoresis on $4 \%$ polyacrylamide gels (containing $2.5 \%$ glycerol) at $150 \mathrm{~V}$ for $2 \mathrm{~h}$ in $0.5 \times \mathrm{TBE}$ buffer.

\section{Footprinting analysis}

The distal and proximal Sf1 promoter fragments were generated by PCR using one nonlabeled and one ${ }^{32} \mathrm{P}$-labeled primer (distal fragment: P5s, GGGGAAGCTTCACACCCTTAGCCCAGCA GT, P5as, CAGAGGCCAAGGCACTGGAG; proximal fragment: P3s, CTCCAGTGCCTTGGCCTCTG, P3as, TTTTGGA TCCTCCCAGGCCTCAGGTAGGGC). For the characterization of WB2, a PCR-generated fragment encompassing nt -350 to -50 was used. In each case, a $5^{\prime}$ - as well as a $3^{\prime}$-labeled fragment was analyzed. PCR fragments were gel-purified, and probes $(10,000 \mathrm{cpm})$ were incubated with $50 \mu \mathrm{g}$ of GST, GSTWT1(-KTS), GST-WT1(+KTS), and GST-LHX9HD, respectively, in binding buffer $\left(100 \mathrm{mM} \mathrm{KCl}, 1 \mathrm{mM} \mathrm{MgCl}_{2}, 10 \mu \mathrm{M}\right.$ $\mathrm{ZnSO}_{4}, 10$ mM Tris, $\mathrm{pH} 7.5$, 4\% glycerol, $0.1 \%$ Triton X-100, 1 $\mathrm{mM}$ DTT) for $30 \mathrm{~min}$ at room temperature. Samples were treated with RQ1-DNase I (Promega) in a total reaction volume of $100 \mu \mathrm{L}$, and digestion was terminated after $3 \mathrm{~min}$ by adding $90 \mu \mathrm{L}$ prewarmed $\left(37^{\circ} \mathrm{C}\right)$ stop solution $(200 \mathrm{mM} \mathrm{NaCl}, 30 \mathrm{mM}$ EDTA, $1 \%$ SDS, $100 \mu \mathrm{g} / \mathrm{mL}$ yeast RNA). DNA fragments were phenol/chloroform-extracted, ethanol-precipitated, and separated by electrophoresis on a $6 \%$ polyacrylamide sequencing gel in $1 \times$ TBE buffer. The sequence of the protected region was determined by alignment with a sequencing reaction using a Thermo Sequenase radiolabeled terminator cycle sequencing kit (Amersham) with the primer which was labeled in the respective footprinting reaction.

\section{Generation and analysis of transgenic mice}

Mice carrying the $L a c Z$ gene under the control of a fragment of the murine $S f 1$ promoter were generated by standard pronuclear injection into fertilized eggs (Hogan 1994) and maintained on a C57BL/6J background. The construct Sf1-blue was made by PCR reaction on murine genomic DNA as a template using the primers SFlpr/as (TTTTGGATCCTCCCAGGCCTCAGGTA GGGCA) and SF1pr/s (GGGGAAGCTTCACACCCTTAGC CCAGCAGTC). The primers harbor nt -589 to -570 and +66 to +85 of the $S f 1$ promoter sequence (Woodson et al. 1997) and carry a BamHI and a HindIII site, respectively. The PCR product was cloned into the pGEM-T easy vector (Promega), released with HindIII and NcoI, and ligated into the vector pSKT-NLSLacZ. This vector provides the $L a c Z$ gene carrying a nuclear localization signal at the $\mathrm{N}$ terminus (Bonnerot et al. 1987). For the introduction of mutations, the QuikChange kit (Stratagene) was used. All four WT1-binding sites within the Sf1 promoter fragment were successively mutated by using the oligonucleotides described in the legend of Figure 3 . The resulting construct was named $S f 1$-white. The integrity of all constructs was verified by sequencing.

For the Sf1-blue mice (wild-type Sf1-promoter), a total number of 20 (in the case of the Sf1-white mice [mutated Sf1-promoter], nine) transgenic mice were generated, and in both cases lines derived from seven males were established and characterized. In each case, one of the founder animals did not produce offspring. Whereas two founders of the Sf1-blue did not pass on the transgene and one did not show any transgene expression, in the remaining three lines, transgene expression could be observed in the gonad. All six remaining mouse lines with the mutated Sf1-white construct expressed the transgene in the spinal cord but not in the gonad. In each line, expression of the transgene was analyzed using at least 15 transgenic embryos.
Mice were genotyped by PCR using primers SF1pr/s3 (GATC GGACAGGGCCAGTTTC) and LacZrev (AGACCATTTTCAA TCCGCACC). Transgene expression was assayed by X-gal staining of embryos following standard procedures (Hogan 1994). After completion of the color reaction, the embryos were washed 3 times in PBS and post-fixed in $4 \%$ paraformaldehyde for $30 \mathrm{~min}$, washed in PBS, and transferred to $80 \%$ glycerol/PBS for storage and photography. Alternatively, samples were dehydrated, embedded in paraffin, and cut into 7- $\mu \mathrm{m}$ transverse sections. Sections were dewaxed, rehydrated, and stained with eo$\sin$. For the immunohistochemical assays, a rabbit anti-SF1 antibody (1:200 dilution) was used as primary antibody, and the sections were treated as described (Ikeda et al. 2001). The immunoreactivities with biotinylated secondary antibody (Vector) were detected using the VIP substrate kit (Vector).

\section{Acknowledgments}

We thank Falk Weih and Michael Pankratz for discussions and for reading and improving this manuscript and K.-I. Morohashi for providing the antiserum against SF1. We also thank Birgit Besenbeck, Nathalie Decker, Stephan Brodbeck, Stephanie Wiessner, and Debra Weih for their excellent technical support. A special thanks goes to the animal house staff, in particular Norma Howells, Selma Huber, and Stephanie Wiessner. Without their enthusiasm, this project would not have been possible. This work was supported by grants from the Deutsche Forschungsgemeinschaft (En 280/2-4) and the Deutsche Krebshilfe (101741-En 2) to C.E.

The publication costs of this article were defrayed in part by payment of page charges. This article must therefore be hereby marked "advertisement" in accordance with 18 USC section 1734 solely to indicate this fact.

\section{References}

Achermann, J.C., Ito, M., Hindmarsh, P.C., and Jameson, J.L. 1999. A mutation in the gene encoding steroidogenic factor- 1 causes XY sex reversal and adrenal failure in humans. Nat. Genet. 22: 125-126.

Arango, N.A., Lovell-Badge, R., and Behringer, R.R. 1999. Targeted mutagenesis of the endogenous mouse Mis gene promoter: In vivo definition of genetic pathways of vertebrate sexual development. Cell 99: 409-419.

Armstrong, J.F., Pritchard-Jones, K., Bickmore, W.A., Hastie, N.D., and Bard, J.B. 1992. The expression of the Wilms' tumour gene, WT1, in the developing mammalian embryo. Mech. Dev. 40: 85-97.

Barbaux, S., Niaudet, P., Gubler, M.C., Grunfeld, J.P., Jaubert, F., Kuttenn, F., Fekete, C.N., Souleyreau-Therville, N., Thibaud, E., Fellous, M., et al. 1997. Donor splice-site mutations in WT1 are responsible for Frasier syndrome. Nat. Genet. 17: 467-470.

Bardoni, B., Zanaria, E., Guioli, S., Floridia, G., Worley, K.C., Tonini, G., Ferrante, E., Chiumello, G., McCabe, E.R., Fraccaro, M., et al. 1994. A dosage sensitive locus at chromosome $\mathrm{Xp} 21$ is involved in male to female sex reversal. Nat. Genet. 7: 497-501.

Belo, J.A., Bouwmeester, T., Leyns, L., Kertesz, N., Gallo, M., Follettie, M., and De Robertis, E.M. 1997. Cerberus-like is a secreted factor with neutralizing activity expressed in the anterior primitive endoderm of the mouse gastrula. Mech. Dev. 68: 45-57.

Birk, O.S., Casiano, D.E., Wassif, C.A., Cogliati, T., Zhao, L., 
Zhao, Y., Grinberg, A., Huang, S., Kreidberg, J.A., Parker, K.L., et al. 2000. The LIM homeobox gene Lhx9 is essential for mouse gonad formation. Nature 403: 909-913.

Bonnerot, C., Rocancourt, D., Briand, P., Grimber, G., and Nicolas, J.F. 1987. A beta-galactosidase hybrid protein targeted to nuclei as a marker for developmental studies. Proc. Natl. Acad. Sci. 84: 6795-6799.

Call, K.M., Glaser, T., Ito, C.Y., Buckler, A.J., Pelletier, J., Haber, D.A., Rose, E.A., Kral, A., Yeger, H., Lewis, W.H., et al. 1990. Isolation and characterization of a zinc finger polypeptide gene at the human chromosome 11 Wilms' tumor locus. Cell 60: 509-520.

Cook, D.M., Hinkes, M.T., Bernfield, M., and Rauscher III, F.J. 1996. Transcriptional activation of the syndecan-1 promoter by the Wilms' tumor protein WT1. Oncogene 13: 17891799.

De Santa Barbara, P., Bonneaud, N., Boizet, B., Desclozeaux, M., Moniot, B., Sudbeck, P., Scherer, G., Poulat, F., and Berta, P. 1998. Direct interaction of SRY-related protein SOX9 and steroidogenic factor 1 regulates transcription of the human anti-Mullerian hormone gene. Mol. Cell. Biol. 18: 66536665.

Englert, C. 1998. WT1-More than a transcription factor? Trends Biochem. Sci. 23: 389-393.

Englert, C., Hou, X., Maheswaran, S., Bennett, P., Ngwu, C., Re, G.G., Garvin, A.J., Rosner, M.R., and Haber, D.A. 1995. WT1 suppresses synthesis of the epidermal growth factor receptor and induces apoptosis. EMBO J. 14: 4662-4675.

Englert, C., Maheswaran, S., Garvin, A.J., Kreidberg, J., and Haber, D.A. 1997. Induction of p21 by the Wilms' tumor suppressor gene WT1. Cancer Res. 57: 1429-1434.

English, M.A. and Licht, J.D. 1999. Tumor-associated WT1 missense mutants indicate that transcriptional activation by WT1 is critical for growth control. J. Biol. Chem. 274: 13258-13263.

Gessler, M., Poustka, A., Cavenee, W., Neve, R.L., Orkin, S.H., and Bruns, G.A. 1990. Homozygous deletion in Wilms tumours of a zinc-finger gene identified by chromosome jumping. Nature 343: 774-778.

Guan, K.L. and Dixon, J.E. 1991. Eukaryotic proteins expressed in Escherichia coli: An improved thrombin cleavage and purification procedure of fusion proteins with glutathione Stransferase. Anal. Biochem. 192: 262-267.

Haber, D.A., Park, S., Maheswaran, S., Englert, C., Re, G.G., Hazen-Martin, D.J, Sens, D.A., and Garvin, A.J. 1993. WT1mediated growth suppression of Wilms tumor cells expressing a WT1 splicing variant. Science 262: 2057-2059.

Haber, D.A., Sohn, R.L., Buckler, A.J., Pelletier, J., Call, K.M., and Housman, D.E. 1991. Alternative splicing and genomic structure of the Wilms tumor gene WT1. Proc. Nat1. Acad. Sci. 88: 9618-9622.

Hammes, A., Guo, J.K., Lutsch, G., Leheste, J.R., Landrock, D., Ziegler, U., Gubler, M.C., and Schedl, A. 2001. Two splice variants of the Wilms' tumor 1 gene have distinct functions during sex determination and nephron formation. Cell 106: 319-329.

Herzer, U., Crocoll, A., Barton, D., Howells, N., and Englert, C. 1999. The Wilms tumor suppressor gene wt 1 is required for development of the spleen. Curr. Biol. 9: 837-840.

Hogan, B. 1994. Manipulating the mouse embryo: A laboratory manual. Cold Spring Harbor Laboratory Press, Plainview, NY.

Ikeda, Y., Shen, W.H., Ingraham, H.A., and Parker, K.L. 1994. Developmental expression of mouse steroidogenic factor-1, an essential regulator of the steroid hydroxylases. Mol. Endocrinol. 8: 654-662.
Ikeda, Y., Takeda, Y., Shikayama, T., Mukai, T., Hisano, S., and Morohashi, K.I. 2001. Comparative localization of Dax-1 and Ad4BP/SF1 during development of the hypothalamic-pituitary-gonadal axis suggests their closely related and distinct functions. Dev. Dyn. 220: 363-376.

Jurata, L.W. and Gill, G.N. 1998. Structure and function of LIM domains. Curr. Top. Microbiol. Immunol. 228: 75-113.

Kawabe, K., Shikayama, T., Tsuboi, H., Oka, S., Oba, K., Yanase, T., Nawata, H., and Morohashi, K. 1999. Dax-1 as one of the target genes of Ad4BP/SF1. Mol. Endocrinol. 13: 1267-1284.

Kikuchi, H., Takata, A., Akasaka, Y., Fukuzawa, R., Yoneyama, H., Kurosawa, Y., Honda, M., Kamiyama, Y., and Hata, J. 1998. Do intronic mutations affecting splicing of WT1 exon 9 cause Frasier syndrome? J. Med. Genet. 35: 45-48.

Kim, J., Prawitt, D., Bardeesy, N., Torban, E., Vicaner, C., Goodyer, P., Zabel, B., and Pelletier, J. 1999. The Wilms' tumor suppressor gene (wt1) product regulates Dax-1 gene expression during gonadal differentiation. Mol. Cell. Biol. 19: 2289-2299.

Klamt, B., Koziell, A., Poulat, F., Wieacker, P., Scambler, P., Berta, P., and Gessler, M. 1998. Frasier syndrome is caused by defective alternative splicing of WT1 leading to an altered ratio of WT1 +/-KTS splice isoforms. Hum. Mol. Genet. 7: 709-714.

Kreidberg, J.A., Sariola, H., Loring, J.M., Maeda, M., Pelletier, J., Housman, D., and Jaenisch, R. 1993. WT-1 is required for early kidney development. Cell 74: 679-691.

Lee, S.B., Huang, K., Palmer, R., Truong, V.B., Herzlinger, D., Kolquist, K.A., Wong, J., Paulding, C., Yoon, S.K., Gerald, et al. 1999. The Wilms tumor suppressor WT1 encodes a transcriptional activator of amphiregulin. Cell 98: 663-673.

Luo, X., Ikeda, Y., and Parker, K.L. 1994. A cell-specific nuclear receptor is essential for adrenal and gonadal development and sexual differentiation. Cell 77: 481-490.

Mayo, M.W., Wang, C.Y., Drouin, S.S., Madrid, L.V., Marshall, A.F., Reed, J.C., Weissman, B.E., and Baldwin, A.S. 1999. WT1 modulates apoptosis by transcriptionally upregulating the bcl-2 proto-oncogene. EMBO J. 18: 3990-4003.

Menke, A.L., van der Eb, A.J., and Jochemsen, A.G. 1998. The Wilms' tumor 1 gene: Oncogene or tumor suppressor gene? Int. Rev. Cytol. 181: 151-212.

Moore, A.W., Schedl, A., McInnes, L., Doyle, M., HecksherSorensen, J., and Hastie, N.D. 1998. YAC transgenic analysis reveals Wilms' tumour 1 gene activity in the proliferating coelomic epithelium, developing diaphragm and limb. Mech. Dev. 79: 169-184.

Nachtigal, M.W., Hirokawa, Y., Enyeart-VanHouten, D.L., Flanagan, J.N., Hammer, G.D., and Ingraham, H.A. 1998. Wilms' tumor 1 and Dax-1 modulate the orphan nuclear receptor SF1 in sex-specific gene expression. Cell 93: 445454.

Nakagama, H., Heinrich, G., Pelletier, J., and Housman, D.E. 1995. Sequence and structural requirements for high-affinity DNA binding by the WT1 gene product. Mol. Cell. Biol. 15: 1489-1498.

Parker, K.L., Schimmer, B.P., and Schedl, A. 1999. Genes essential for early events in gonadal development. Cell Mol. Life Sci. 55: 831-838.

Pelletier, J., Bruening, W., Kashtan, C.E., Mauer, S.M., Manivel, J.C., Striegel, J.E., Houghton, D.C., Junien, C., Habib, R., Fouser, L., et al. 1991a. Germline mutations in the Wilms' tumor suppressor gene are associated with abnormal urogenital development in Denys-Drash syndrome. Cell 67: 437-447.

Pelletier, J., Bruening, W., Li, F.P., Haber, D.A., Glaser, T., and Housman, D.E. 1991b. WT1 mutations contribute to abnor- 
mal genital system development and hereditary Wilms' tumour. Nature 353: 431-434.

Raymond, C.S., Murphy, M.W., O'Sullivan, M.G., Bardwell, V.J., and Zarkower, D. 2000. Dmrt1, a gene related to worm and fly sexual regulators, is required for mammalian testis differentiation. Genes \& Dev. 14: 2587-2595.

Reddy, J.C., Hosono, S., and Licht, J.D. 1995. The transcriptional effect of WT1 is modulated by choice of expression vector. J. Biol. Chem. 270: 29976-29982.

Reddy, J.C. and Licht, J.D. 1996. The WT1 Wilms' tumor suppressor gene: How much do we really know? Biochim. Biophys. Acta 1287: 1-28.

Riccardi, V.M., Sujansky, E., Smith, A.C., and Francke, U. 1978. Chromosomal imbalance in the Aniridia-Wilms' tumor association: 11p interstitial deletion. Pediatrics 61: 604-610.

Swain, A. and Lovell-Badge, R. 1999. Mammalian sex determination: A molecular drama. Genes \& Dev. 13: 755-767.

Thate, C., Englert, C., and Gessler, M. 1998. Analysis of WT1 target gene expression in stably transfected cell lines. Oncogene 17: 1287-1294.

Wang, Z.Y., Qiu, Q.Q., Enger, K.T., and Deuel, T.F. 1993. A second transcriptionally active DNA-binding site for the Wilms tumor gene product, WT1. Proc. Natl. Acad. Sci. 90: 8896-8900.

Woodson, K.G., Crawford, P.A., Sadovsky, Y., and Milbrandt, J. 1997. Characterization of the promoter of SF1, an orphan nuclear receptor required for adrenal and gonadal development. Mol. Endocrinol. 11: 117-126.

Yu, R.N., Ito, M., Saunders, T.L., Camper, S.A., and Jameson, J.L. 1998. Role of Ahch in gonadal development and gametogenesis. Nat. Genet. 20: 353-357. 


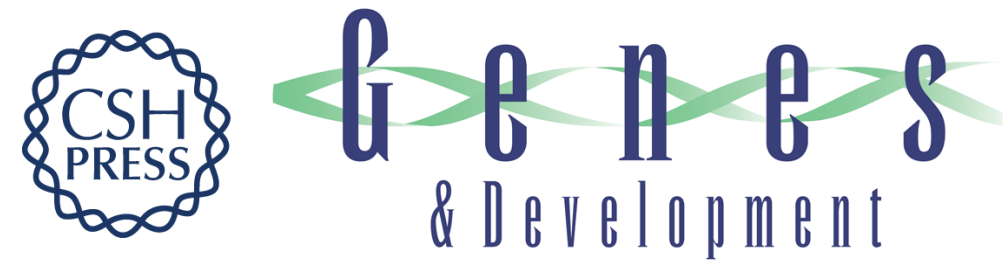

\section{The Wilms tumor suppressor WT1 regulates early gonad development by activation of Sf1}

Dagmar Wilhelm and Christoph Englert

Genes Dev. 2002, 16:

Access the most recent version at doi:10.1101/gad.220102

References

This article cites 48 articles, 14 of which can be accessed free at: http://genesdev.cshlp.org/content/16/14/1839.full.html\#ref-list-1

License

Email Alerting

Receive free email alerts when new articles cite this article - sign up in the box at the top Service right corner of the article or click here.

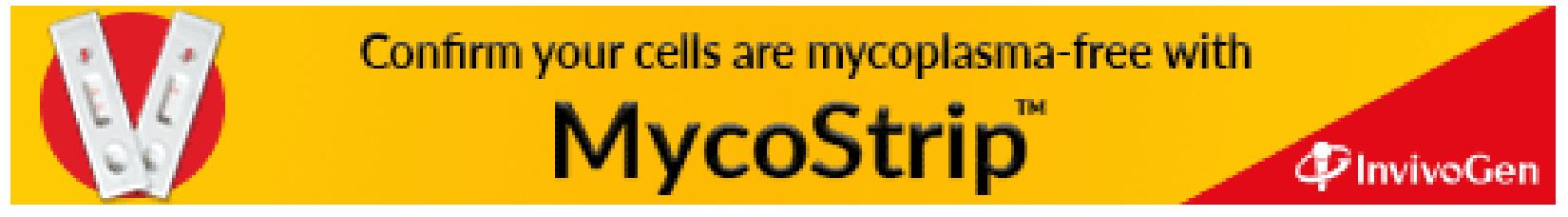

